\title{
Establishing Multi-level Performance Condition Indices for Public Schools Maintenance Program Using AHP and Fuzzy Logic
}

\author{
Mohamed MARZOUK ${ }^{1}$, Ehab AWAD ${ }^{2 *}$ \\ ${ }^{1}$ Dept. of Structural Engineering, Cairo University, \\ Giza, 12613, Egypt, \\ mm_marzouk@yahoo.com \\ 2 Orascom Construction, \\ 2005 A Corniche El Nil, Cairo, 11221, Egypt, \\ ehab.awad@orascom.com (*corresponding author)
}

\begin{abstract}
This research targets the creation of indices to enforce standard assessment for group of educational buildings and to set common understanding of facilities' condition among different stakeholders. This model contains four levels of performance assessment that deal with program, facility, package, and element. AHP-fuzzy model is built using linguistic expression to represent condition of asset. The proposed model generates standard indices for three levels (element, package, and facility) which are aggregated to provide realistic condition assessment for a group of facilities (program). For evaluation of this model, a case study is presented with data from 21 schools in Giza governorate-Egypt to provide these indices. Example for assessment of two elements is worked out to illustrate the feasibility of this model. Outputs could be used by management as part of the decision support system.
\end{abstract}

Keywords: AHP, Fuzzy Logic, Facility Assessment, Educational facilities, Condition index.

\section{Introduction}

In Egypt, the total number of students attending public schools is 17.990 .836 representing $90 \%$ of the total student population with 414.258 classrooms (MOE 2016). Managing maintenance of that large network of educational assets requires the built up of necessary measurement standard for assessing building conditions with minimizing the bias of human judgment. This research provides a methodology for establishing multi-levels performance condition indices for public schools maintenance program using AHP and fuzzy logic. The methodology enables the following:

1. Setting process for developing and generating four indices with providing proposed action. These condition performance indices can be applied for assessment of group of educational buildings on different levels. These levels are, program which is the highest level which include group of facilities, facility, which includes group of spaces, and Package which consists of elements with similarity in trades like finishing and mechanical. Finally, element like floor or openings which is the lowest level to be assessed; and it is evaluated based on Inspection of its properties.

2. Enabling systematic data collection with reducing biasness. This is done by implementing standard steps for evaluation of each element within facility.

3. Upon completion of process, different stakeholders like facility user, decision makers, and program managers should have common understanding regarding asset condition and proposed maintenance program main goals.

\section{Literature Review}

Many researchers covered school assets from different perspectives. Uline and Moran (2007) confirmed the link between quality of educational facility and student achievement in English and Mathematics. Jeong et al (2013) presented model for prediction of environmental impact at the early stage of project to reduce negative consequences on the building during operation stage. For several types of infrastructure assets, condition index is key component in the structure of the maintenance management system. Marzouk and Abdelaty (2014) presented BIM-based framework for assessing condition of subway stations. Owners of road assets have pioneering 
status in assessing condition of pavement which is widely known as pavement condition index. In North America, departments of transportation have standard road management system that provided asset managers with tool to evaluate pavement condition; and therefore, being able to apply further analysis to estimate required plans for maintenance and rehabilitation. ASCE (2013) provided report card for assessment of infrastructure assets through United States. Several indices exist to assess condition of different types of infrastructure like roads, water mains, bridges etc. However, creating standard index for measuring performance of group of different types of public facilities is not possible due to huge differences among them in design, size, and function. The problem also exists within same type of asset. Gharaibeh et al (2010) investigated the common agreement among different departments of transportation regarding pavement condition index implementation concluding huge disagreement among different indices. For building assessment, Facility condition index is one of the essential tools in maintenance and rehabilitation assessment; with main goal is to assess condition of facility based on cost. National Association of Colleges and Universities Business Officers (NACUBO) (2016) defines facility condition index as "the ratio of building deferred conditions divided by building replacement (i.e., if the deferred maintenance is greater than the replacement cost (over 1), the structure might warrant demolition rather than repair)". Equation 1 shows the method of calculating this index

$$
\text { Facility Condition Index }=\frac{\text { Cost of Deficiencies }}{\text { Current replacement Value }}
$$

Roberts (2009) discussed assessment of facilities from two different perspectives engineering and teaching. Outcomes revealed that engineering assessment were not linked to quality of teaching. Establishment of assessment model requires the use of several techniques. One of such important tools is analytical hierarchy processes (AHP). AHP has been applied in numerous construction industry applications that were related to decision making problems including assessment of infrastructure assets. AHP is a theory of measurement for establishing weight system based on judgments of experts to derive priority scales (Saaty 2008). This was done by enabling pair wise comparison among group of attributes on same level. Marzouk and Moselhi (2002) adopted AHP as part of bidding study for assisting contractors in estimating competitive markup. AHP was implemented for performing scale build up among different criteria that were part of bidding markup decisions (AbouRizk et al, 1996). Vavataskios and Anagnostopoulos (2006) developed model for assessing construction contractors who apply for public projects; the model was built considering AHP for enabling minimizing failure of project and ensuring contractors' capabilities. Şerbu and Borza (2014) implemented AHP for evaluating technological factors that affect introduction of new technologies for rural areas. Podgorski (2014) introduced AHP model for key performance indicators selection for occupational safety and health management. Fuzzy logic applications included modeling of performance assessment for water pipelines (EL Chanati et al, 2016), and condition assessment of corrosion of reinforced concrete building (Mitra et al., 2010.

\section{Proposed Methodology}

The methodology adopted for this research consists of three main stages. The first stage is literature review of different AHP and fuzzy logic applications in infrastructure asset management system with close review regarding the use of standard condition assessment for evaluation of different types of infrastructure. The second stage is developing AHP-fuzzy model combining AHP concept and fuzzy logic control for processing data collected from field. Standard index is created in the third stage to provide conclusive assessment about condition of asset through four multi-level indices. Finally, a case study is presented to validate the use of the model. For maintenance management of distributed network of educational facilities, a breakdown of their components is necessary to perform standard condition assessment. Each facility consists of group of spaces. OmniClass ${ }^{\mathrm{TM}}$ space by function table describes space as" a part of the built environment that is marked off in some way". Facility consists of physical number of spaces. Space has specific function, location, and type. Each space contains number of elements that are assigned for inspection; this could be window, door, floor, painting, plaster, etc. Elements must be part of space to 
be assessed. Any element within facility must exist in one space. For standard assessment of element, inspector needs to check properties of element like floor surface. Or sub-elements which are grouped as element; for example, window element can be broken-down into frame, inner frame, glass, accessories, and wire mesh. With this breakdown, element could be checked, assessed, and maintained based on completion of gathered data for these components. Finally, the aggregation of these data could be done from two perspectives:

1. to assess data for one element through the whole facility or program; and,

2. to classify all elements under five groups:
a. structure,
b. finishing,
c. outdoor,
d. mechanical, and
e. electrical.

This concept also enables different approaches for developing maintenance plan by specialized group of professions.

\subsection{Educational facility condition assessment model}

AHP-fuzzy logic control model is developed to process received data from field, and to generate score that can be compared to standard index. Components of Model are:

1. weight system on different levels to be the base for aggregation of scores,

2. standard benchmark index for comparing different outputs with it,

3. set up fuzzy rules based on number of elements per each package,

4. selecting membership function,

5. establishing scale for fuzzification of linguistic terms,

6. selecting method of defuzzification, and

7. presenting guidelines for proposed action based on generated score.

\subsection{Weights of program levels}

Weights are generated within different levels of the program. AHP method is applied on subelement levels to enable assessment of elements like doors and window. On the elements level, elements with similarity are grouped together in one of five packages. Weight system is set to support aggregation of score per package.

On the package level, a third weight system is used to support process of facility condition index output. AHP method is applied to establish all these standard weights. Feedback from 14 domain experts to provide assessment based on pair wise comparison to reflect relative importance among entities per each level of asset. As per Saaty (2008) a scale of 1 to 9 is set to enable expert from determining pairwise importance value. Consistency ratio $(C I C I)$ is calculated to ensure the creditability of the received values. Saaty recommended that CICI should be less than 10\% (Ermini and Ataoui, 2014). This approach is applied from sub-element level till level of package, i.e., three weight system are established. Criteria for comparison between elements are the priority for maintainability. Performing the AHP method on the proposed element with considering the designated package resulted in generation of weight system among them as shown in Table 1. The output weight is based on the average of all the participants.

Table 1. Developed Relative Weight System based on AHP method

\begin{tabular}{|c|c|c|}
\hline Weight (\%) & Element & Package \\
\hline 63.9 & Column (CL) & \multirow{3}{*}{ Structure } \\
\hline 25.5 & Beam (BM) & \\
\hline 10.6 & Slab (SL) & \\
\hline 40.1 & Floor (FL) & \multirow{4}{*}{ Finishing } \\
\hline 21.0 & Painting \& Plaster (PP) & \\
\hline 22.6 & Windows (WD) & \\
\hline 16.3 & Doors (DR) & \\
\hline 29.7 & External Plaster (EP) & \multirow{3}{*}{ Outdoor } \\
\hline 28.7 & Roof (RF) & \\
\hline 41.6 & Stair (SR) & \\
\hline 41.4 & Water Main (WM) & \multirow{4}{*}{ Mechanical } \\
\hline 30.8 & Sewer Main (SM) & \\
\hline 18.2 & Toilets Fixtures(WA) & \\
\hline 9.6 & Greywater System (GW) & \\
\hline 32.8 & Light Fixtures(LF) & \multirow{3}{*}{ Electrical } \\
\hline 44.2 & Electricity System (ES) & \\
\hline 23.0 & Room Ventilation (RV) & \\
\hline 40.0 & Structure (ST) & \multirow{5}{*}{$\begin{array}{l}\text { Overall } \\
\text { facility }\end{array}$} \\
\hline 17.4 & Finishing (FI) & \\
\hline 11.8 & Outdoor (OD) & \\
\hline 15.4 & Mechanical (MC) & \\
\hline 15.4 & Electrical (EL) & \\
\hline
\end{tabular}


Table 2 includes also the Consistency ratio that did not exceed $10 \%$ as per Saaty recommendation.

Table 2. Consistency Ratio Results per each Matrix

\begin{tabular}{|c|c|c|r|}
\hline \multicolumn{3}{|c|}{ Consistency Ratio } & \multirow{2}{*}{ Matrix } \\
\hline Min & Max & Average & Structure \\
\hline $0.0 \%$ & $9.0 \%$ & $2.9 \%$ & Finishing \\
$2.1 \%$ & $7.9 \%$ & $4.4 \%$ & Outdoor \\
$0.0 \%$ & $6.8 \%$ & $2.4 \%$ & Mechanical \\
$0.0 \%$ & $5.7 \%$ & $2.6 \%$ & Electrical \\
$0.0 \%$ & $9.8 \%$ & $2.1 \%$ & Packages \\
$0.2 \%$ & $4.7 \%$ & $2.3 \%$ & \\
\hline
\end{tabular}

\subsection{Standard condition assessment scale}

Setting standard scale for condition of element is very challenging task. This is due to absence of standard reference for assessing elements' condition of public school facility based on physical condition. Unlike common approach that depends on cost of maintenance versus the current value of the asset using facility condition index (FCI), the purpose of this scale is to assess the functionality of element. For proceeding with assessment, four scales need to be compared with standard index. To achieve that target, interviews with three experts were performed to get their judgment to rank three different proposed standard scales. The selected experts have both academic and field experience in management. Experts performed evaluation based on their experience to select the best scale that can be relevant for assessing elements' condition of public educational facility. The proposed scales range from completely poor to excellent with different range for each state. These three scales are listed as follows in Table 3.

Table 3. List of Proposed Scales with their limits

\begin{tabular}{|c|c|c|}
\hline $100 \%$ Excellent & $100 \%$ Poor & No. \\
\hline Excellent $>=70$ & Poor $<=30$ & I \\
\hline Excellent $>=80$ & Poor $<=20$ & II \\
\hline Excellent $>=90$ & Poor $<=10$ & III \\
\hline
\end{tabular}

Based on the experts' opinion, the selected scale is 20-80 which include gradual change from poor to good after 20 and gradual increase of excellent from 50 till 79 , as over 80 the facility is considered in excellent condition till the end of scale at 100. Table 5 lists the conclusion outcome of experts' evaluation by describing the

Table 5. Description of Condition that is Based on Expert Evaluation for Standard Scale

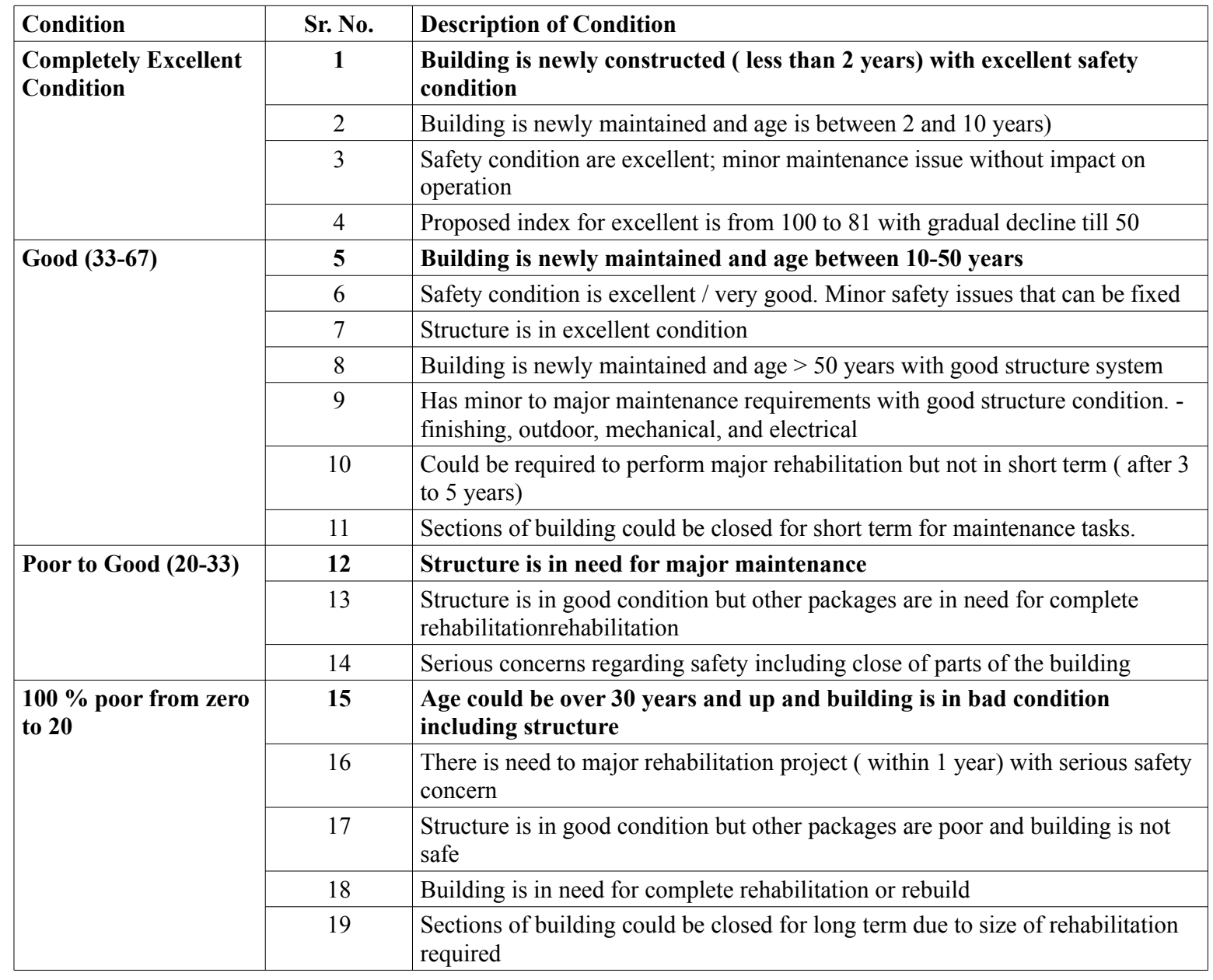


expected signs of each condition. This selection enables the base to setting multi-levels performance indices. Assessment of program condition can be divided into four levels:

1. program which is global performance for the network,

2. facility which cover entire building with all its contents,

3. package, which cover group of similar elements for example, structure or finishing, and

4. element for example, windows, doors, and floor. Table 6 shows purpose of each index.

Table 6. List of Performance Indices with Purpose

\begin{tabular}{|c|l|l|}
\hline No. & $\begin{array}{c}\text { Level of } \\
\text { Index }\end{array}$ & \multicolumn{1}{|c|}{ Purpose } \\
\hline I & Program & $\begin{array}{l}\text { Provide one condition index for } \\
\text { group of educational assets }\end{array}$ \\
\hline II & Facility & Provide condition of whole asset \\
\hline III & Package & $\begin{array}{l}\text { Index for assessing group of } \\
\text { relevant elements, for example, } \\
\text { structure and finishing }\end{array}$ \\
\hline IV & Element & $\begin{array}{l}\text { This index targets element and its } \\
\text { properties. }\end{array}$ \\
\hline
\end{tabular}

\subsection{Fuzzy model for condition assessment}

Fuzzy Logic provides ability to process the gathered data from field either on linguistic or numeric from with robust ability to deal with ambiguity and inaccuracy. The function of the fuzzy model is to turn the linguistic assessment input into quantified figure as input for fuzzy processing to generate quantified condition assessment of the element or the package. Such output enables the establishment of the multilevel indices for element, package, facility, and program. To develop the fuzzy model for condition assessment, three components of this model are established; membership function, rules, and linguistic scale as described in below sub-sections.

\subsection{Membership function}

Membership function is based on the three condition classification, poor, good, and excellent (see Figure 1). Data is processed based on this function and the output is numeric representation of the condition of the entity. This scale is derived from the interview with expert to select standard condition index. Equations 2, 3, and 4 are the mathematical form for the three conditions of assessment:

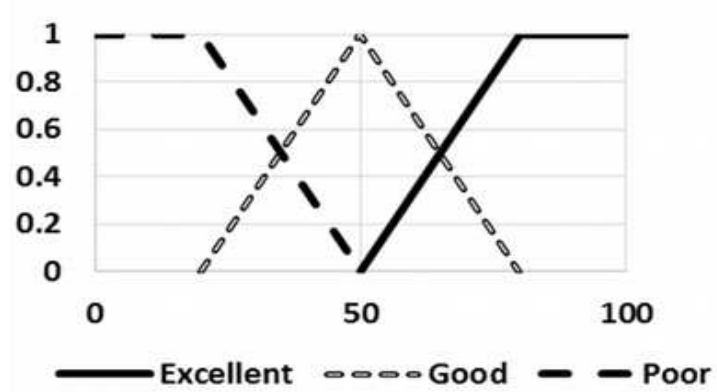

Figure 1: Membership Function for the Fuzzy Model

1. Poor condition is represented by trapezoidal shape and its equation is:

$\mu(x)=\left\{\begin{array}{cc}1, & x \leq 20 \\ \frac{50-x}{30}, & 20<x<50\end{array}\right.$

2. Good condition is represented by triangle shape and its equation is:

$\mu(x)=\left\{\begin{array}{cc}\frac{x-20}{30}, & 20<x<50 \\ 1, & x=50 \\ \frac{x-50}{30}, & 50<x<80\end{array}\right.$

3. Excellent condition is represented by trapezoidal shape and its equation is:

$\mu(x)=\left\{\begin{array}{cc}\frac{x-50}{30}, & 50<x \leq 80 \\ 1, & 80<x \leq 100\end{array}\right.$

\subsection{Generating rules}

Rules are generated on three levels: package level, element level, and sub-element level. For example, to establish all possible rules for condition assessment based on linguistic feedback, if the element has 3 sub-element to be assessed, and the number of conditions is 3 (poor, good, excellent); in this case, total generated rules are $3 * 3 * 3=27$. Table 4 provides sample of rules on package level for mechanical elements and sample for part of rules on window sub-element respectively.

Table 4. Sample of list of rules that are adopted for mechanical packages

\begin{tabular}{|cccccc|}
\hline \multirow{2}{*}{$\begin{array}{c}\text { Rule } \\
\text { No. }\end{array}$} & & \multicolumn{2}{c}{ Elements } & & $\begin{array}{c}\text { Combined } \\
\text { Impact }\end{array}$ \\
\cline { 2 - 6 } & WM & SM & WA & GW & Linguistic \\
\hline 1 & Poor & Poor & Poor & Poor & poor \\
\hline 2 & Poor & Poor & Poor & Good & poor \\
\hline
\end{tabular}




\subsection{Linguistic-numeric scale}

Linguistic-Numeric scale is developed to quantify value for each linguistic assessment term. Range of values per each condition is derived from the membership function. Average value for each condition is calculated to present the condition (see Figure 2). With that, linguistic qualitative assessment can be transformed in a numeric value as input for the fuzzy model.

\begin{tabular}{|l|c|c|c|}
\hline $\begin{array}{l}\text { Equivalent } \\
\text { range of } \\
\text { combination } \\
\text { impact }\end{array}$ & Poor & Good & Excellent \\
& & & \\
$\begin{array}{l}\text { Elements } \\
\text { performance } \\
\text { impact scale }\end{array}$ & 18.6 & 50 & 81.4 \\
\hline
\end{tabular}

Figure 2. Elements' Performance Transformation from Linguistic to Numeric

\subsection{Maintenance action}

One of the major components in the maintenance system is to build, develop, and maintain knowledge base for actions that need to be taken in response for minor or major maintenance issues. Such knowledge base is available to concerned system's users to get knowledge of different experts regarding required action relevant to each condition assessment retrieved from field. It shows the major actions that decision maker could be in need to take to meet specific cases as per Table 7 that provides proposed actions for three state condition of the facility. In real life situation,

Table 7. Evaluation of Performance Index for Facility $\boldsymbol{P}_{\boldsymbol{i}}$

\begin{tabular}{|l|l|l|}
\hline $\begin{array}{l}\text { Performance } \\
\text { Condition } \\
\text { Index P }\end{array}$ & Condition & Proposed Action \\
\hline $81 \leq \mathrm{P} \leq 100$ & Excellent & $\begin{array}{l}\text { Preventive maintenance } \\
\text { or nothing to be done. }\end{array}$ \\
\hline $65<\mathrm{P}<81$ & $\begin{array}{l}\text { Good to } \\
\text { excellent } \\
\text { condition }\end{array}$ & $\begin{array}{l}\text { Regular maintenance with } \\
\text { focus on poor elements }\end{array}$ \\
\hline $35<\mathrm{P} \leq 65$ & $\begin{array}{l}\text { Mainly in } \\
\text { Good State }\end{array}$ & $\begin{array}{l}\text { Rehabilitation in several } \\
\text { packages. The structure is } \\
\text { in good stage. }\end{array}$ \\
\hline $21 \leq \mathrm{P} \leq 35$ & $\begin{array}{l}\text { Major rehabilitation with } \\
\text { considering condition of } \\
\text { structure. }\end{array}$ \\
\hline $\mathrm{P}<21$ & $\begin{array}{l}\text { Complete rehabilitation if } \\
\text { structure is in good } \\
\text { condition; else, complete } \\
\text { demolish and rebuild }\end{array}$ \\
\hline
\end{tabular}

such table should be turned to contain, manuals, procedure, list of actions, 3D model, and all other information that could enable taking correct decision in timely manner.

\subsection{Field Data Processing}

After development of all the components of the model, field data is processed in order to generate numeric condition assessment for subelement, element, or the package as follows:

1. Collect data from field: The field inspector gathers findings using preset forms to provide condition inspection. Such action is done by visiting each space in the facility or according to the type of inspection. For each space, inspector checks existing elements included in it.

2. Use the relative weight and preset rules: This is done to transform the linguistic input into quantified input with adaptation of membership function.

3. Perform defuzzification process: This process is applied on the numeric input through the membership function to generate the output score which is numerical condition score of the element, and package, and facility. The output is the algebraic integration as per Seguno center of gravity (COG) method as in Equation 5. Such process provides indices for these three levels of assessment.

$$
C O G=\frac{\frac{\int_{a}^{b} \mu A(x) d x}{\int_{a}^{b} \mu A^{(x) d x}}}{\mu(x) d x}
$$

4. Generate indices for program and for package through: program condition index is calculated based on weight of each school within the program. This weight is based only on number of classrooms available in each school and formula for that is:

$$
P=\sum_{i=0}^{n} \frac{c_{i} * p_{i}}{C}
$$

Where

- $P$ is the program performance index for group of schools $n$;

$-\quad c_{i}$ is the number of classrooms in school $i$; 
- $\quad C$ is the total number of classrooms in the program;

- $\quad p_{i}$ is the performance index of facility $i$.

For specific package assessment on the level of program, equation 6 is modified to provide this figure.

$$
K=\sum_{i=0}^{n} \frac{c_{i} * k_{i}}{C}
$$

Where

- $K$ is overall performance of package on the level of program. This figure could enable generation of five indices for five packages.

- $k_{i}$ is the performance of package for school $i$

5. Compare output with standard index: Output is generated for the designated entity to provide the current condition of it.

6. Propose action based on outcome: Experts can provide different proposals based on output indices.

\section{Case Study}

\subsection{Case description}

The purpose of this case is to apply developed AHP-fuzzy model for assessment of group of educational facilities and to generate multilevel indices and to provide analysis with proposed action based on the results. The case consists of two parts; the first part is the assessment of the whole group of schools based on condition evaluation of each facility including package and elements. Whereas, the second part presents assessment of window element based on evaluation of their subelement. Data collected for this study have been gathered from 21 schools in Giza - Egypt. These schools are basically 16 elementary, 1 preparatory, and 4 secondary. Data are part of government initiative to assess public schools in Egypt between Dec. 2014 and Feb. 2015. Data included in the assessment covers 17 elements grouped under 5 packages. By applying research methodology, AHP method is implemented to create weight system for the components of facility including package, element as per Table 2 .

\section{2 Modeling case inputs}

Data collected for condition of different elements of the facility are expressed in a linguistic format as a default. Assessment of element is represented by three conditions, poor, good, and excellent. Data is grouped per package to be processed in the fuzzy model. For example, a structure assessment package is derived by evaluating three elements, slab, beam, and column through the whole facility. Input from field is compared to set of normalized rules for structure package. Normalization means that rules are set to create combined condition with considering the relative weight of each element. The result is linguistic condition that is to be transformed to fuzzy value using the linguistic scale. The results are fuzzy numbers that is to be defuzzified using the selected membership function to generate the score of the condition index. Results are compared to the standard condition index to select the proposed action. Same process was made for the overall assessment of the facility.

Table 8. Sequence of process on inputs for Generating Package Condition Index

\begin{tabular}{|c|c|c|c|}
\hline Level & Action & Input & Output \\
\hline 를 & $\begin{array}{l}\text { Collect data in } \\
\text { the field per } \\
\text { element through } \\
\text { the whole } \\
\text { facility } \\
\end{array}$ & $\begin{array}{l}\text { Field } \\
\text { inspection }\end{array}$ & $\begin{array}{l}\text { Linguistic field } \\
\text { assessment, } \\
\text { poor, good, } \\
\text { excellent }\end{array}$ \\
\hline 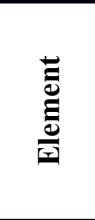 & $\begin{array}{l}\text { Compare to } \\
\text { rules list } \\
\text { normalized } \\
\text { based on the } \\
\text { relative weight } \\
\text { of element }\end{array}$ & $\begin{array}{l}\text { Field } \\
\text { assessment }\end{array}$ & $\begin{array}{l}\text { Quantified } \\
\text { fuzzy score for } \\
\text { the package }\end{array}$ \\
\hline 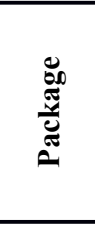 & $\begin{array}{l}\text { Defuzzification } \\
\text { using } \\
\text { membership } \\
\text { function and } \\
\text { center of gravity } \\
\text { method }\end{array}$ & Fuzzy value & $\begin{array}{l}\text { Package } \\
\text { condition index }\end{array}$ \\
\hline 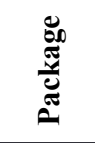 & $\begin{array}{l}\text { Compare output } \\
\text { from the model } \\
\text { with the } \\
\text { standard score }\end{array}$ & $\begin{array}{l}\text { Package } \\
\text { score }\end{array}$ & Proposed action \\
\hline
\end{tabular}

\section{Results and Discussion}

Results are aggregated as per Equation 6 and 7 for overall indices. Output gave three types of indices

1. index per each package through total number of school,

2. index per facility, and

3. overall performance index for 21 schools.

Major target is to enable decision makers from receiving analysis and proposed action based 
on that model. Results shown in Table 9 represent facility condition per school which varies from 23 to 56 . The results reveals 2,8 and 10 are in poor, barely in good and good conditions, respectively. The reason for being in the good zone is that structure system is relatively in very good shape. However, further analysis is required to go package by package to define major problems and proposed action. Table 10 presents the status of packages through all schools along with the proposed action to be applied. Scores calculated using Equation 7 reveals the problem of each one with proposed action by expert. The model is capable to roll up condition assessment starting from elements to provide status of five packages. By reviewing output of mechanical package, it is concluded that huge deterioration is noticeable with clear failure in washrooms. However, this is a design concern that should be treated by strategic decision to go through in-depth review for whole process of engineering, material and construction to meet heavy duty function with big number of users. Finally, the overall condition index for the data set is calculated as per equation 6 and the score is 44 . This result shows the need for performing rehabilitation plan for upgrading most of the schools. With few exceptions, most of the schools need review of mechanical and electrical packages. For windows assessment, data are subset of case study data for 10 schools including 233 spaces with a total of 233 windows. Element's components are brokendown to five sub-elements. Table 11 lists windows sub-elements and their relative weights to each other. Windows overall results are classified including the proposed action as per Table 14. Results showed that none of elements are in excellent condition. Out of 233 elements, 76 are in need for complete replacement. Analysis of results by facility revealed the need for complete set of windows for one facility. Another seven schools have some windows that must be replaced. Finally, windows elements performance requires audit similar to mechanical and electrical elements that includes review of design issue.

\section{Summary}

One of the major challenges in asset management is to provide standard condition index that reflects the condition of the asset with respect to functionality. This research
Table 9. Facility Condition Index per each School

\begin{tabular}{|c|c|}
\hline School No. & Facility Condition Index \\
\hline 1 & 39.7 \\
2 & 39.7 \\
3 & 39.7 \\
4 & 39.6 \\
5 & 39.6 \\
6 & 55.8 \\
7 & 55.8 \\
8 & 55.7 \\
9 & 55.7 \\
10 & 55.7 \\
11 & 55.7 \\
12 & 39.0 \\
13 & 53.8 \\
14 & 23.0 \\
15 & 39.0 \\
16 & 39.0 \\
17 & 54.0 \\
18 & 54.0 \\
19 & 23.0 \\
20 & 54.0 \\
21 & 53.0 \\
\hline
\end{tabular}

Table 10. Score of Packages over 21 School including Analysis and Proposed Action

\begin{tabular}{|l|l|l|}
\hline Package & Score & \multicolumn{1}{c|}{\begin{tabular}{c}
\multicolumn{1}{c|}{ Analysis / } \\
Proposed Action
\end{tabular}} \\
\hline Structure & $\mathbf{5 1 \%}$ & $\begin{array}{l}\text { Good condition, regular } \\
\text { review of items as per the } \\
\text { Egyptian code for concrete. }\end{array}$ \\
\hline Finishing & $\mathbf{3 3 \%}$ & $\begin{array}{l}\text { Declining condition, } \\
\text { rehabilitation program is } \\
\text { needed. Major problem exists } \\
\text { in opening. }\end{array}$ \\
\hline Outdoor & $\mathbf{3 7 \%}$ & $\begin{array}{l}\text { there are significant problems } \\
\text { in roofs and stair including } \\
\text { safety }\end{array}$ \\
\hline Mechanical & $\mathbf{2 1 \%}$ & $\begin{array}{l}\text { Washrooms are in poor } \\
\text { condition. New design is } \\
\text { needed with higher standard }\end{array}$ \\
\hline Electrical & $\mathbf{2 4 \%}$ & $\begin{array}{l}\text { Significant failure, } \\
\text { replacement of boxes, boards, } \\
\text { and ventilation units. }\end{array}$ \\
\hline
\end{tabular}

Table 11. Window Components Weights

\begin{tabular}{|l|l|c|}
\hline \multirow{1}{*}{ Element } & \multicolumn{1}{|c|}{ Sub-Element } & Weights \\
\hline \multirow{5}{*}{ Windows } & Frame & $\mathbf{4 0 \%}$ \\
\cline { 2 - 3 } & Sliding panel & $\mathbf{2 3 \%}$ \\
\cline { 2 - 3 } & Glass & $\mathbf{1 2 \%}$ \\
\cline { 2 - 3 } & Accessories & $\mathbf{2 0 \%}$ \\
\cline { 2 - 3 } & Fly screen & $\mathbf{6 \%}$ \\
\cline { 2 - 3 } & Total & $\mathbf{1 0 0 \%}$ \\
\hline
\end{tabular}

provided a measure system that is divided into four levels of indices, program, facility, package, and element level. AHP-fuzzy logic model was built to generate such indices. The 
Table 12. Classification of Windows Condition Index and Proposed Actions

\begin{tabular}{|c|c|c|l|}
\hline Condition & Score & $\begin{array}{c}\text { Number } \\
\text { of } \\
\text { elements }\end{array}$ & Proposed Action \\
\hline Excellent & $80<\mathrm{P} \leq 100$ & 0 & None \\
\hline Good & $35>\mathrm{P} \leq 80$ & 157 & $\begin{array}{l}\text { Major maintenance } \\
\text { with some repair; } \\
\text { some elements } \\
\text { need replacement. }\end{array}$ \\
\hline Poor & $0 \leq \mathrm{P} \leq 35$ & 76 & $\begin{array}{l}\text { Complete } \\
\text { replacement is } \\
\text { recommended }\end{array}$ \\
\hline \multicolumn{2}{|c|}{ Total } & $\mathbf{2 3 3}$ & \\
\hline
\end{tabular}

process for establishing the model were performed in five main stages:

1. set of weight system among different elements,

2. data collection,

3. run fuzzy model to generate score of condition indices for element and package,

4. Generate facility and program condition indices , and

5. Propose action.

A case study was presented to show the applicability of model by assessing 21 schools in Giza Governorate - Egypt. The outputs provided overall condition indices on the whole group, facility, and package. For windows, indices were generated using subset of the data. Results prove the ability of the model in assessing all other elements within public school facility by following the same steps. The model implementation provided realistic method to evaluate public schools facilities. Yet, more development is needed to include more elements like outdoor fences, light pole, and roads, and to study environmental impact on schools.

\section{REFERENCES}

1. ASCE, Report Card for America's Infrastructure 2013, American Society of Civil Engineers. Aval. at www.infrastruct urereportcard.org (accessed April 1, 2016).

2. DOZZI, S. P., S. M. ABOURIZK, S. L. SCHROEDER, Utility-Theory Model for Bid Markup Decisions, Construction Engineering and Management, vol. 122(2), 1996, pp. 119-124.

3. EL CHANATI, H., M. EL-ABBASY, F. MOSLEH, A. SENOUCI, M.
ABOUHAMAD, I. GKOUNTIS, T. ZAYED, H. AL-DERHAM, MultiCriteria Decision Making Models for Water Pipelines, Performance of Constructed Facilities, vol. 30(4), 2016.

4. ERMINI, R., R. ATAOUI, Computing a Global Performance Index by Fuzzy Set Approach, Procedia Eng., vol. 70, 2014, pp. 622-632.

5. GHARAIBEH, G., Y. ZOU, S. SALIMINEJAD, Assessing the Agreement among Pavement Condition Indexes, Transportation Engineering, vol. 136, 2010, pp. 765-772.

6. JEONG, K., C. JI, C. KOO, T. HONG, H. PARK, A Model for Predicting the Environmental Impacts of Educational Facilities in the Project Planning Phase, Cleaner Prod., vol. 107, 2015, pp. 538-549.

7. MARZOUK, M., A. ABDELATY, BIMbased Framework for Managing Performance of Subway Stations, Automation in Construction, vol. 41(1), 2014, pp. 70-77.

8. MARZOUK, M., O. MOSELhI, A Decision Support Tool for Construction Bidding, Construction Innovation, vol. 3(2), 2003, pp. 111-124.

9. MITRA, G., K. JAIN, B. BHATTACHARJEE, Condition Assessment of CorrosionDistressed Reinforced Concrete Buildings using Fuzzy Logic, Performance of Constructed Facilities, vol. 24(6), 2010, pp. 562-570.

10. MOE, Annual Statistics Book 2014-2015, Egypt Ministry of Education, available at http://emis.gov.eg/annual_book.aspx? $\mathrm{id}=400$ (accessed March $\overline{15}, 2016)$.

11. NACOCU, Terms and Glossary; Facilities and Sustainability Related, National Association of College and Universities, available at http://www. nacubo.org/Documents/business_topics/Gl ossaryTermsFacilitiesSustainability.pdf (accessed April 30, 2016).

12. PODGORSKI, D., Measuring Operational Performance of OSH Management System - A Demonstration of AHP-based Selection of Leading Key Performance Indicators, Safety Science, vol. 73, 2015, pp.146-166. 
13. ROBERTS, L., Measuring School Facility Conditions: an Illustration of the Importance of Purpose, Journal of Educational Administration, vol. 47(3), 2009, pp. 368-380.

14. SAATY, T. L., Decision Making with analytic Hierarchy Process, International Journal of Services Sciences, vol. 1(1), 2008, pp. 83-98.

15. ŞERBU, R., BORZA S., Achieving Sustainable Competitive Advantage of Romanian Rural Area by Integrating Information
Interdisciplinary Approach, Studies in Informatics and Control, vol. 23(2), 2014, pp. 215-222.

16. ULINE, C., MOREN, M., The Walls Speak: the Interplay of Quality Facilities, School Climate, and Student Achievement, Educational Administration, vol. 46(1), 2006, pp. 55-73.

17. VAVATSKIOS, A. P., K. P. ANAGNOSTOPOUlOS, An AHP Model for Construction Contractor Prequalification, International Journal of Op. Research, vol. 6(3), 2006, pp. 333-346. 